\title{
(Re)Assembling Anti-Oppressive Practice Teachings in Youth and Community Work through Collective Biography (2)
}

\author{
Rick Bowler ${ }^{1}$, Steph Green ${ }^{2}$, Christine Smith ${ }^{3, *}$ and Liz Woolley ${ }^{1}$ \\ 1 Community and Youth Work Studies, Faculty of Education and Society, University of Sunderland, \\ Sunderland SR6 0DD, UK; rick.bowler@sunderland.ac.uk (R.B.); liz.woolley@sunderland.ac.uk (L.W.) \\ 2 Community Development and Youth Work, Oxford OX3 9BZ, UK; sgreen@ruskin.ac.uk \\ 3 Faculty of Arts Cultures and Education, University of Hull, Hull HU6 7RX, UK \\ * Correspondence: christine.smith@hull.ac.uk
}

Citation: Bowler, R.; Green, S. Smith, C.; Woolley, L. (Re)Assembling Anti-Oppressive Practice Teachings in Youth and Community Work through Collective Biography (2). Educ. Sci. 2021, 11, 497. https://doi.org/ 10.3390/educsci11090497

Academic Editors: Pam Alldred and Frances Howard

Received: 16 June 2021

Accepted: 24 August 2021

Published: 3 September 2021

Publisher's Note: MDPI stays neutral with regard to jurisdictional claims in published maps and institutional affiliations.

Copyright: (c) 2021 by the authors. Licensee MDPI, Basel, Switzerland. This article is an open access article distributed under the terms and conditions of the Creative Commons Attribution (CC BY) license (https:/ / creativecommons.org/licenses/by/ $4.0 /)$.

\begin{abstract}
This article draws on research undertaken as part of a Collective Biography project generated by a group of activists and lecturers teaching and researching in youth and community work (YCW). Collective Biography (CB) is an approach to research in which participants work productively with memory and writing to generate collective action orientated analysis. The emphasis on collectivized approaches to $\mathrm{CB}$ work acts as a potential strategy to disrupt and resist the reproduction of power in academic knowledge-making practices and the impact of powerful policy discourses in practice. The article explores the current context and contemporary challenges for teaching antioppressive practice in UK based universities before briefly scoping out the methodology of CB. Extracts from a memory story are used as an example of the process of collective analysis generated through the process of $\mathrm{CB}$ in relation to racism, the role of anti-oppressive practice, and as the basis for YCW educators to think collectively about implications for teaching going forward. The article goes on to explore the role of concepts that were worked with as part of the CB process and considers the potential significance for teaching anti-oppressive practice in YCW. The article concludes by starting to scope out key considerations relating to the potential role of $\mathrm{CB}$ as a grass roots strategy to open spaces of possibility alongside young people and communities in reassembling the teaching of anti-oppressive practice in YCW.
\end{abstract}

Keywords: youth and community work; social justice; anti-oppressive practice; collective biography; agential cuts; memory; diffraction

\section{Introduction}

Teaching anti-oppressive practice in Youth and Community Work (YCW) in Higher Education (HE) is a messy business. The article starts in the middle of a theoretical and practice terrain that is fraught with contestation and is as complex as it is dynamic. YCW educators and students located in UK based HE institutions are routinely immersed within narratives of individualization and responsibilization [1]. These narratives are deeply embedded and internalized within the practices of the neo liberal university which at the same time are intersecting with new formations of social inequalities and oppression re-carved along old fault lines of social division [2]. Increasingly, YCW educators and their methods and methodologies, shaped by Freire's [3] notion of critical pedagogy, are precariously positioned in the neo liberal university with frequent reminders of the potential of being both 'replaceable and renewable' [4] (p. 909). These contexts run counter to $\mathrm{HE}$ as emancipatory and transformational [3]. This holds intended and unintended consequences for approaches to teaching anti-oppressive practice orientated to social justice as part of critical pedagogy in YCW. Instead, it is creating conditions in which educators are vulnerable to 'colonise their own practices while being anxious about the implications of doing otherwise' [4] (p. 909). 
The article is based on the premise that there is a political and ethical imperative for youth and community educators to develop teaching strategies to 'do otherwise' [4] (p. 909) as a push back to increasingly overly colonized performative teaching spaces in HE [1]. This requires a commitment to be proactive in developing collective ways of working as a community of practice and to work creatively with concepts in ways that disrupt the reproduction of academic knowledge-making practices and deficit-based policy discourses [5]. It is within these contexts that the article draws on a process of CB [6] incorporating memory work, writing, and analysis generated by a group of activists and lecturers teaching and researching in YCW across universities in the UK (United Kingdom). The process of $\mathrm{CB}$ was an endeavor to lean into the current challenges and tensions encountered within teaching practices and opening space to explore possibilities.

\section{Background Context and Literature}

Since YCW became a degree profession in 2008, anti-oppressive practice continues to be both in the middle and increasingly on the margins of ethical and political struggles about how and to what extent teaching and practice should engage with broader societal concerns relating to social justice [7]. What constitutes professionally qualifying YCW education cannot be understood as if it is a fixed object conceived in an ahistorical, apolitical vacuum, disconnected and decontextualized from the realities of young people's lived experiences.

There are a multiplicity of stakeholders invested in constructing, validating, maintaining, and regulating professionally qualifying YCW education and in shaping spaces for learning. Youth and community programs located in universities are inevitably subject to multi-directional and competing pressures to engage with the profession and its diverse youth and community practices in the context of changing social, economic, and political landscapes [8]. Students often want to know what they 'need to learn' to successfully complete their qualifying degree program and get a job aligned to government policy and employer's expectations. There is an uneasy alliance between this and the call, integral to critical pedagogy, that underpins youth and community programs, to challenge oppressive systems and structures and to devise anti-oppressive ways of working that are transformative and oriented to social justice [3].

\section{In the Middle and on the Margins}

Powerful policy discourses and associated performativities in practice have cast anti-oppressive practices, and the conceptual framing of them, to the margins at a time when new formations of oppression and injustice are emergent [2]. The shift from social democracy to neoliberalism has facilitated the breakdown of traditional forms of collective organizing and a general erosion of investment in youth and community services. This has given rise to new narratives, underpinned by powerful moral deficit discourses, with both continuities and breaks from the past [9]. In the 21st century new challenges associated with a post-industrial society include but are not limited to globalized changes to work, mass migration, demographic changes, epidemics, rising concerns about security, escalating inequality, and oppression [9]. Youth loneliness, mental health, and violence are magnified as symbolic of a broken society and the advance of technology increases the scope for surveillance and management of 'disordered' individuals [10].

The scale of inequalities, abuses, and injustices experienced by young people in contemporary times makes for compelling evidence that there is an ongoing need for anti-oppressive practice as a way of 'doing' YCW [2]. The profound changes that are taking place within a globalized, advanced capitalist society [2] require critical analysis of the ways in which anti-oppressive approaches to youth and community practices are being theorized and put to work.

A preliminary review of literature as part of $C B$ work over the last decade revealed an eclectic, rich, and diverse field of writing woven through books, journal articles, and reports referring to anti-oppressive practice in YCW from different angles and from across 
disciplines drawing on critical race theory, feminism, queer studies, critical disability studies, and post-colonial theories [11]. These areas of critical study all arose from the margins of academic discourse as positions from which to critique oppressive practices in dominator systems [11]. As in the academy, the dominator discourse about young people's concerns is primarily driven by government policy and an economic imperative. Under these neoliberal domains, the challenging of oppression thus becomes adrift from systemic and structural forces into a problem of competing individualized personal choices.

Despite significant movements in recent decades to push anti-oppressive practice into the middle of a way of 'doing youth and community work', it remains both in and out of focus. Seal [12] (p. 263) notes for example that 'in the light of late modern, postmodern and post-critical debates there has been a difficulty in establishing a coherent theoretical framework for both critical pedagogy and YCW.' This article extends that reflection to incorporate a consideration of similar challenges in theory building for anti-oppressive practice. Williams, at a critical social policy conference, provided useful analytical points to orientate the contemporary and necessary theoretical work required to address the difficulties outlined by Seal [12]. She calls for an approach that 'recognises diversities in patterns of power but one which does not fall into the trap of establishing a hierarchy of oppressions' [13] (p. 16). The task she affirmed is to relate the diversity and differences between forms of oppression on the one hand to a need for an anti-oppression alliance on the other [13] (p. 16). The intersectional thinking that came from the collective conversations by the authors in this article endorse that position.

At the time of writing this across different contexts and in response to different contemporary social movements such as Black Lives Matter and calls to decolonize the curriculum, there is evidence that the YCW sector has entered a moment of critical reflection about the need to reimagine both the possibilities of teaching [8] and future directions as a professional practice. In May 2021, for example, the Institute for Youth Work facilitated a student led conference. Participants explored the extent to which the hierarchies within the sector, youth and community workers, and those teaching and training in YCW were representative of the communities of young people that they serve. Issues were also raised about whether the National Occupational Standards [14] were equipping students to be effective in practice and whether they need updating, especially given their failure to explicitly articulate anti-oppressive practice. A representative of the National Youth Agency in response to concerns raised about the lack of focus upon power, privilege, and access to opportunity within the sector, stated that 'we are not very good at anti-oppressive practice' with a call to work collaboratively to be proactive in redressing this. This accords with Banks's [15] writing in an editorial piece in 2008, in which she raised questions about the theory and practice of ethics which are central to anti-oppressive practice. As relevant in 2021 as in 2008, she asks whether 'education and training programmes, textbooks and research findings provide students with effective tools that they can actually use to guide and resolve them in practice' [15] (p. 54). This can potentially provide an impetus and call for those researching, writing, teaching, and practicing in YCW to work collaboratively to open space to take stock and make connections of where we want to get to in terms of our teaching anti-oppressive practice, what it is designed to do, and what possibilities are opened in working creatively with concepts [6]. At a time when oppression, discrimination, and intolerance of difference is on the rise both in the UK and globally [16] there is a danger that the forging of deep divisions between theory and practice gives way to anti-intellectual times whilst waving the banner of social justice [17]. What constitutes anti-oppressive practice as a way of doing youth and community work is a deeply political matter. Seal [18] calls for the creation of 'Alliances for creating new knowledge'. Working collaboratively in alliance holds the potential to enable collective sense making of the serious challenges that lie ahead. This is especially important given the precarious nature of youth and community education within the neoliberal university and the scale of oppressions experienced disproportionately by young people. The CB work is one approach to working across boundaries to address the limitations of theories and concepts in relation to 21st century challenges, the 
impact on young people and communities, and to reassembling anti-oppressive practices as part of this.

\section{Methodology and Methods}

The CB project was undertaken as part of one of the participant's doctoral research during a global pandemic and two UK wide lockdowns in the period June 2020-May 2021. The University of Plymouth Education Research Ethics Sub-Committee granted ethical approval for the project in May 2020. In total, nine participants from across seven universities were recruited via an initial email request to participate, followed by a more detailed information sheet and briefing session which also provided details of the right to withdraw and anonymity. Participants were all members of the UK based Professional Association of Lecturers in Youth and Community Work (PALYCW) and had experience in researching and/or teaching anti-oppressive practice on professionally qualifying undergraduate degree programs in $\mathrm{YCW}$.

The CB process followed a 'describable pattern, revisable in practice' [6] (p. 8) and due to the pandemic was developed online via Microsoft Teams rather than face to face. The pattern included 'researching and constructing memory questions,' 'structuring workshops,' 'memory telling,' 'memory writing,' and 'reading memory stories. This describable pattern acted as loose organizing principles that informed the research [6]. In practice this translated into two cycles of $\mathrm{CB}$ where participants negotiated and agreed on the focus for memory work, a further dialogical session exploring the role of theory and concepts in opening possibilities for teaching anti-oppressive practice and a smaller group who engaged in a process of extended dialogue and writing of which this article is one of the outcomes.

In the first cycle of $\mathrm{CB}$, participants worked with their own memories of discrimination and oppression, in the second, they explored how academics are situated in the neo liberal university and experiences of teaching anti-oppressive practice in that context. The third session worked with memory stories that had been generated in the first two cycles of $C B$ and worked with them in relation to agential realism and the allied theoretical concepts of memory and diffraction, considering their relevance to teaching anti-oppressive practice in YCW. The approach to CB was a development on from the earlier collective memory work led by Haug [19] in the 1980s. For Davies and Gannon [6], individual stories take on a significance in the production of knowledge about how individuals are made social or how we are made (post) human [20]. Through a process of CB, participants worked productively with memory making, dialogical, and writing activities to explore the relations of power, politics, identity, and recognition. The activities were developed collectively and collaboratively to find ways to move beyond the humanistic boundaries of selfhood and Cartesian nature/culture dualisms [11]. The approach taken to CB work prioritized the process of relationship building and collaboration as crucial elements in creating conditions of trust that facilitated community solidarity and participation. The memory work developed from within lived experiences considering implications for theory as practice. This approach offered a way of engaging with theory that was not abstracted from lived experience but flexible, revisable, workable, and orientated to action. The aim was to locate new openings and possibilities for thinking about teaching practices in relation to anti-oppressive practice. The methodology aligns well with the principles of YCW with its emphasis on the processual and relational nature of approach and the possibilities this opens for new insights and theorizations.

\subsection{Challenges and Limitations in Practice}

There are several challenges and ethical considerations associated with the development of $\mathrm{CB}$ work that require both commitment and active engagement from participants in working them through as part of the process. It is beyond the scope of this article to engage in an in-depth discussion about some of the challenges and limitations encountered through the process of $\mathrm{CB}$ work as this is still subject to further exploration and analysis. 
There are some initial reflections including that the CB approach is time and resource intensive which is often limited for those teaching and researching in HE. Due to the pandemic, the $\mathrm{CB}$ process was developed through a series of online interactions rather than face to face and carried out over a longer period rather than intensively face to face through a writing retreat [6]. The move to an online approach to CB work did make the process more accessible as participants were not restricted geographically. The process was however no less demanding of time, resources, and a high level of emotional engagement in collectively sharing and working with memories. The process required a significant level of trust, intimacy, and a willingness to be vulnerable which was made more challenging in an online environment. The silences and discomfort in the online virtual space were, for example, more intensified than in physical spaces. Differences between participants, conflict, and disagreement were more easily glossed over in online CB work when further time and space was required to explore those differences in greater depth. Within any CB process including this one there will be power differentials as participants will come into the space with a multiplicity of experiences, differing levels of time, seniority, shared histories, and working relationships which can influence and shape how participants feel able to engage with the process [6]. Ethics in this research was understood as a negotiated relational process between participants and throughout the process. Time and space were built into agreed intentionality within sessions and there was a commitment to navigate differences carefully, with respect, recognition, and with the option to call time at any point [6].

\subsection{The Process of $C B$, Findings, and Discussion}

The process of $\mathrm{CB}$ generated memory stories, extended collective writing, and analysis developed from within participants' experiences of teaching anti-oppressive practice as part of professionally qualifying youth and community education programs. The memory work for the purposes of this article and the theoretical work and analysis emerging through the process is constituted as both data and findings. The CB work is at an early stage of development. Multiple lines of inquiry were worked with in depth generating rich materials. This section of the article offers an initial partial unfolding of memory, writing, and analysis as 'data and findings' in relation to that work and is organised into two parts. The first part provides an example of memory work, writing and analysis in relation to racism, anti-racism, and the teaching of anti-oppressive practice. The second part explores key concepts that were worked with through the process of $\mathrm{CB}$, exploring the potential to extend analysis and open possibilities for teaching anti-oppressive practice. Participants negotiated the focus for memory work. The first cycle focused on experiences of oppression informed by an agreed brief:

Individual memory stories can include for example smells, sounds, touch, taste and focus on body parts, clothing, technology, music. Once you have decided on a memory try to capture this in as much detail as possible including the context of when, where were you, sensations, feelings etc. There is no right or wrong in the writing of an individual memory story.

Participants spent time generating their own individual memory story:

The place of my birth was Newcastle upon Tyne in 1956. The same year the White Defence League formed when it broke away from the League of Empire Loyalists. I hope they felt my birth. I most certainly came to feel their violent ideological hatred. I have lived with their logics in action for the whole of my life. We were born in the same nation, in the same timeframe. Thus, began my journey with the imposition and weight of systematised oppressions and the inner desire to be anti-oppressive and develop opposition and resistance to all forms of unjust authority.

Working in small groups individual memory stories were explored through dialogue again in relation to an agreed brief: 
It will be important once you have written the memory story that you arrange to share with your group so that the process of rewriting into the third person can be begin by asking questions/seeking clarifications.

Following this individual memory, stories were exchanged so that each person was responsible for rewriting a memory story into the third person.

The lessons learnt about the British state and the state of Britain in relation to its violent eugenicist histories to sterilise and cleanse ... . keep clean, do not mix, work but always be marked and defined as subhuman. The desire is to whitewash the planet, impose supremacist and purist ideations .... these discursive practices are given scientific justifications within the academy.

The process of rewriting individual memory stories into the third person was designed to engage in a process of putting the individual subject under erasure, to expose relations of power, politics, identity, and recognition [6]. Through a process of writing memory stories were developed into extended analysis. The writing process was punctuated by further moments of dialogue and reflection between participants through emails, via telephone, and in virtual sessions in small and large groups. What follows is an extract of an extended analysis developed through the process.

\section{Writing into the Process}

The importance of YCW more accurately remembering the connectivity of the historical to contemporary sites for struggle against racism's reality is produced here. In this his/her/our story, the importance of the Black and South Asian Youth Movements and their resistance against British white supremacist racism makes visible how YCW struggled to learn from young people [21-25]. The memory story is brought into relationship with social movements of resistance to racism and all intersecting systematic forces of privilege which brought young people's material and concrete experiences to bear on the YCW profession to develop a statement of purpose. The pivotal moment chosen as a point of departure from our current state of near silence in the shrouding of the purpose and value of anti-oppressive praxis, is the 1991 definition of youth work cited in Davies [26] and the periods before and after its promise. The statement of purpose tells us that youth work should redress all forms of inequality and ensure equality of opportunity through the challenging of oppressions such as racism and sexism and all those which spring from difference of culture, race, language, sexual identity, gender, disability, age, religion, and class.

At this time anti-oppressive practice as a conceptual tool was in the ascendancy, boosted by the political support from progressive social movements and the rise of municipal anti-racism within local government structures. This definition was ambitious for youth services to achieve alone but was borne out of the wider struggles for justice and 'more traditional forms of resistance' to discrimination [26]. In challenging oppressive forces such as racism, three important studies into the needs of young Black people [27-29] identified a major challenge for youth services because the youth service was white, male, and mono-cultural. These moments of intersecting consciousness and the politics of empowerment [30] need remembering in the depoliticized and decontextualized politics of the current moment.

Under the jurisdiction of racist education, it remains imperative that questions are asked about what truth claims and social reality are being created. It is this analysis where the 'illusions of choice' [27] (p. 141) need to be exposed if racism is to be located and known. Under a system described by bell hooks [31] (p. 4) as 'imperialist, white supremacist capitalist patriarchy', how YCW understands anti-oppressive practice requires recognition of the intersecting dominating cultures in which difference can easily become discursively produced as hateful extremism [32]. Working with memory stories reflected in the extracts italicized above enabled different phenomena to be brought into relationship including history, 'race,' racisms, geographical location, policies, and norms. The processes made 
visible that whilst oppressive practices such as hateful extremism impact on the individual, the system of oppression simultaneously targets collectives. This cognizance of oppression as collective and systemic places a responsibility onto the YCW field to theorize practice in ways that give recognition that young people are never outside of the situated, contextual, communal, and societal realities where meanings are made.

Everyday racisms are the frame for enabling the ongoing acts of racist violence and therefore YCW praxis must be cognizant of the historicity of the problem at the heart of our concern. It is important that we 're/member that targeted and individualized violence is always given cover by the commonplace exclusionary structural and cultural practices where 'micro-aggression' becomes an everyday experience' [33]. The logics of 'race' posited as natural with essential characteristics, forged in and out of the 19th century period of racial science, was built upon ideas and categorizations of what it meant to be, and therefore who could be, human [11]. This was wrought in the elite Eurocentric white and male Enlightenment period [34]. These pasts reverberate into the present and whitewashing the walls to clean them from memory does not challenge the privileges arising from them. Rutherford [35] (p. 186) sums up the complexity when he identifies that 'Race is real because we perceive it. Racism is real because we enact it. Neither race nor racism has foundations in science.' This leaves us all to know that 'racism is a set of social relationships' [34] (p. 14) where the logics of white supremacy, produced through relations of power, were used to justify the transatlantic slave trade, the imperialist expansion of European territories and the brutality of colonial rule. These persist today to deny the full reality of British history and its relationship with racist ideologies and practices that funded its wealth. How the fictions of 'race,' the perpetuation of everyday enactments of racism, and the defense of racist cultures persist, are central questions for YCW professionals to engage with.

One of the practical difficulties for YCW education and training is the absence in most formal educational curricula of explorations of Britain's relationship with racism [36,37]. These absences, which create ignorance and division, are illuminated by a British government pandering to racisms and creating policies that specifically encourage a hostile environment articulated through the lens of nationhood and belonging [38]. Practitioners in developing anti-oppressive praxis for YCW must always be cognizant of the systems of power that organize culture and order conduct in the everyday lives of youth workers, young people, and the encounters they have in the communities where they work, live, and play. How the vertical lines of authority occupy the spaces where young people and youth workers encounter difference is of absolute importance to our pedagogical practice.

Anti-oppressive practice must therefore also turn its concern to the intersectional as well as the simultaneous individualizing, communal impact that is a central connection for YCW practitioners. As Sinclair [39] (p. 22), identified, 'Life experiences [ ... ] form the foundation for each person to build an analytic framework to view, understand, analyse and take action in the real world'. Anti-oppressive practice is thus about developing an analytic frame that can make sense of experience and engage in actions that both dream of and seek to make the world a better place. In relation to anti-racism YCW must critically engage in a discussion about historical/systemic practices such as whiteness, focused on how this system orders the lives of young people in contemporary British society [40].

What happens if we analyze whiteness diffractively? Here, we need to become cognizant of the activity and outcomes of whiteness as a source of systemic privileging power that colonizes our daily encounters with each other. Moments from the past and memories of those moments become purposeful devices to explore ways to develop diffractive practices to escape from the confines of individual immobilization. This can potentially happen when we use the anchors of our past to create a different lens from which to enliven and reconnect us to the central purposes of our ethical work alongside young people. How whiteness is unpicked in relation to anti-oppressive practice illustrates one aspect of the difficult terrain YCWs need to tread when engaging young people in challenging white logic. How Black and other global majority youth workers and their white peers come to 
know race, speak race, and understand race across the different geographies in Britain, is central to our concern.

If race is not openly discussed by white people and white people believe racism is outdated or only concerns black and other global majority people whilst racist cultures and practices persist into the present, then a contradiction arises in the profession's responsibility to ensure all its workforce are racially literate. Whiteness as an ideology and system of privileging endows white people with investments they accrue whether they want them or not. Anti-oppressive practice must work to dismantle the system that bolsters the colonizing ideas and processes woven into the imperialist white supremacist, patriarchal, capitalist system. How we frame anti-oppressive practice is important to where we take it as a cornerstone of YCW praxis in order to (re)assemble anti-oppressive praxis. This notes that oppression requires a collapsing of the binary between theory and practice necessitating ongoing inquiry and theorization in practice.

The extended writing on racism and whiteness emerged from the memory work through the $\mathrm{CB}$ process enabling participants to find ways to begin to work towards unsettling and decolonizing taken for granted thinking and practices. The focus of the collective biography work was 'towards what things do, rather than 'what they are;' towards processes and flows rather than structures and stable forms; to matters of power and resistance; and to interactions that draw small and large relations into assemblage' [41] (p. 407). The process of collective biography provided an orientation and a strategy for navigating complexity in relation to anti-oppressive practice. The process of inquiry enabled recognition of a range of forces at play simultaneously and spanning different temporal and spatial dimensions to produce analysis in action [41].

\subsection{New Materialism, Agential Realism, Intra-Action, and Diffraction}

The second part of the findings section draws on new materialism and explores key concepts that were worked with giving initial consideration as to why these were significant in the process of $\mathrm{CB}$ work. The $\mathrm{CB}$ work was intimately connected to participants teaching practices, informed by critical pedagogy, the concept of praxis [3], and their own contexts within HE institutions in terms of how they were ethically and politically situated within material environments. This was considered by participants to be centrally important to the commitment to disrupt taken for granted ways of working practices vulnerable to a creep towards technical rational approaches to teaching.

Participants considered the role of concepts in enlarging spaces of possibility in analysis and in practice [6]. New materialism and post-humanism draw on a constellation of concepts and theories which have shifted focus to social production [41] and which signal an ontological turn to the material and concrete impact of oppression reflected in the memory writing about racism. This enabled participants to turn attention to what oppression is doing, how it is interfering, disrupting, and shaping lived experiences. In the extract of extended writing, it was the material and concrete impacts of accounts of racism in the writing and analysis that had productive possibilities, enabling potential in the theorization of anti-oppressive practices in action. Barads [42] work on agential realism is significant in working with this potential as it demonstrates the interconnectedness and continual interplay between knowledge-making practices, epistemology, ontology, ethics, and material impacts. This holds implications for how ethics can be understood and enacted through a research process. Barad [42] (p. 90) describes this as a performative and relational 'ethico-onto-episteme-ology'; in other words, 'we cannot think epistemology and ontology separately', they are intimately connected and always emergent in 'intra-action.'

The memory writing developed into extended analysis in the previous section is a demonstration of a means of developing action in ways that enable 'collective knowing and doing' [42] (p. 66) to make a difference. Agential realism unsettles the idea that there is a subject/object relationship between researcher and researched. This conceptualization enabled participants to begin to find alternative ways of thinking about the relationship 
between the approach that they took to $\mathrm{CB}$ work and writing and how this connected to their everyday teaching practices. This contrasts with the usual 'interaction' which assumes that there are separate individual agencies that precede their interaction. The notion of intra-action recognizes that distinct agencies do not precede, but emerge through, their intra-actions. It is important to note that the 'distinct' agencies are only distinct in a relational, not an absolute, sense as agencies are only distinct in relation to their mutual entanglement; they do not exist as individual elements [42] (p. 33). Throughout the writing process participants used Barad's [42] notion of agential cuts to make ethical decisions about their knowledge-making practices and the difference that they felt this was making in their practices. Agential cuts can be described as 'knowledge-making practices.' 'Cutting' in involves the active construction of boundaries within any given research process and making decisions about what is brought into relationship [41,42]. Agential cuts are inherently exclusionary and require an ongoing commitment to tuning into ethical considerations including those of unintended consequences. This article can be read, for example, as a series of agential cuts that are intended as non-hierarchical and subject to ongoing negotiations in dialogues across space and time [41-43]. The cuts made into the memory work on racism are not intended as a linear fixed presentation of 'the truth' or 'facts'. Rather, they are a careful ethical unfolding of meaning-making about matters that impinge on the teaching of anti-oppressive practice in the neoliberal university: what it does and what it can potentially do.

\subsection{Memory}

According to Huyssen [44] (p. 2) memory is 'one of those elusive topics we all think we have a handle on but as soon as we try to define it, it starts slipping and sliding, eluding attempts to grasp it either culturally, sociologically, or scientifically'. Braidotti [11] asserts that without 'a freeing from humanist frameworks' memory is rendered inadequate in being able to realize its radical and political potential to productively engage with a number of contemporary issues. Those contemporary issues are interconnected with 21st challenges, including, for example, the recent global pandemic, ecological challenges, poverty and hunger, the nation state, the changing nature of technology, and the productive role of memory in the process of resistance for justice, equality, representation, and recognition [11]. Drawing on Braidotti's [11] analysis of memory, what can be remembered, what is recollected, and forgotten cannot be understood merely as a process unfolding from within an individual physical body. Memory is not bound by physical bodies: it is relational, processual, nonlinear, and multi directional, with affective capacity across space and time [11]. This makes it possible to move between and beyond the Cartesian separation of mind and body as memory is understood as always existing in the present to orientate actions in the future. As such, there is a constant interplay between past, present, and future across space and time as reflected in the memory writing presented in the previous section.

Memory practices generated from the grass roots expose the power at play when memory is presented as fixed. Memory has a social and collective dimension that is integral to the making and remaking of ideas in intra-action [42]. It engages all the senses, smell, touch, sight, hearing, and taste, and in this framing has radical and political potential for action [11]. The ethical dimension of memory is intimately connected with 'our collective voices' in relation to what and how we are enabled to remember. Recent debates about decolonization serve as a powerful reminder of the role of official memory in manufacturing subjectivities, in shaping the political landscape as well as social relationships, social bonds, and obligations one to another. Collective memories about that which has gone before are continually being reworked in the present with a view to the future. Memory plays a role in the knowledge-making process and is developed intra-actively across space and time. St Pierre describes these kind of ethics as 'invented within each relation as researcher and respondent negotiate sense-making' [45] (p. 186). 


\subsection{Diffraction}

Integral to the approach of $\mathrm{CB}$ was a focus on the discursive ways through which lived experiences became embodied and remembered with intentionality. This was not about presenting what could be remembered or (re)formed as a 'reliable truth' but gave recognition to a shared sense of how individual experiences are constituted in relation to a range of human and non-human matters. The memory work was approached through stories of lived experiences which were written individually, then re-membered, and written about by others in the group. Memory was a diffractive tool [42] interpreted through each person's current contexts and understandings and was a starting point from which to develop a collective fiction, based in remembered 'facts'. This created a dynamic collection of meanings and understandings of oppression and anti-oppressive practices which enabled collective and divergent meanings of events to emerge. The collective 'grid' through which accounts of experiences travelled, bent them to expose the effects of differences at play simultaneously across different and temporal dimensions [41,46]. Through the process of writing participants were able to produce analysis in action rooted in their own practices. Participants were mindful of why some differences are made to matter more than others as the basis for action and 'as an act of courage not to follow the lines laid down by neo liberalism but to sink into the act of writing and to allow the body to take you to think the as yet unthought' [47] (p. 93).

The theory base of YCW (amongst other professions) uses the concepts of reflection and reflexivity [3] and this constitutes a significant strand of teaching in professionally qualifying YCW programs. 'Seeing' ourselves clearly and being conscious of how we are in relation to others is important in practice, but there is more to do before this process can create an anti-oppressive practice. Adding to the metaphor of reflection, the concept of diffraction is a useful tool. Diffraction shows up the effect of differences in what otherwise appears as a homogeneous body. It creates rainbows rather than fractures or hierarchies. It is a valuable analytical tool in a critical, collective, intersectional, anti-oppressive practice. Haraway states "A diffraction pattern does not map where differences appear, but rather maps where the effects of difference appear" [42] (p. 72).

Social change is constant, yet oppression has resilient patterns. The relations of power and control over human and non-human actors of our planet (e.g., land, water, air, living creatures, and all other matter) are devastating the planet and oppressing the majority of people [11]. As explored in the memory writing in the previous section, patriarchy, imperialism, and capitalism have persisted over centuries, yet are subject to change; constantly face challenges; and are not inevitable, eternal, or natural. Antioppressive practice is often couched in terms of individual axes of oppression including class, race, gender, sexuality, disability, and age. The identity politics that come with this has always been self-limiting as the intersectional [30] entanglements get knotted when any movement gains momentum. Everyone has a class, race, gender, disability, age, and sexuality and patterns of oppression diffract through the effects of all these differences. These knots of entanglement get collective movements for change stuck, but if taken account of fully, these entanglements can create knots that bind to give strength and structure to movements-however transitorily.

\section{Conclusions}

The levels of disadvantage and oppression experienced by young people and communities, exacerbated by COVID-19, across social divisions makes for compelling evidence of why ethical, values driven, critically reflective, and anti-oppressive practice continues to occupy an important space within the lexicon of YCW. The anti in anti-oppressive practice implies a proactive position is taken up by YCWs that is explicitly opposed to oppression in all its various guises and that this is reflected in the discursive ways in which teaching practices are shaped and created as the basis for action. Anti implies a call to activism, a commitment to be proactive in creating alliances and working collaboratively across networks and alongside young people and communities to develop practitioner strategies 
that give recognition to lived experiences and unsettle taken for granted assumptions about ways of doing YCW. Teaching YCW must be understood as emerging from within the context of relationships informed by values and ethics that underpin the profession. Those practices, whilst developing from within and emerging out of analysis of structural inequalities, are also at the same time operating in intra-action [42] and are always situated, contextual, relational, and processual [6] (p. 26). Working with concepts to develop analysis of how power operates to inform strategies for practice is central to anti-oppressive practice and the operationalization of a YCW's commitment to social justice [48] (p. 51). Working creatively with concepts as part of a process of $\mathrm{CB}$ offers the potential to develop, tune into, and enact political alliances from the grass roots in dynamic and creative ways so that anti oppressive practices 'Contribute to the transformation of conditions which make injustice possible' [49] (p. 53).

The commitment to work collectively to explore anti-oppressive teaching practices was a commitment to engage in a process of 'doing otherwise' described earlier in the article. The process of collective biography opened a space to explore the complex context in which teaching anti-oppressive practice takes place and how YCW educators are positioned within the neo liberal university. YCW educators are not immune to forces of discrimination and oppression and the internalization of narratives of individualization and responsibilization embedded in the practices of the neo liberal university. CB is an approach to research that is orientated to disrupt those narratives and taken for granted ways of teaching in HE. The approach is challenging, requires commitment, and is resource and time intensive. CB does, however, offer a strategy to develop knowledgemaking practices that are generated from grass roots practices starting where people are at. As Davies et al. [47] (p. 100) states, 'the only place we can speak from is where we are grounded .... our feet on the ground, breathing the air around us, walking through and in our local places.... In starting from where I am I write from my everyday world to connect with yours as the basis for action.'

The CB work is in its initial stages of development. There is recognition that there is further theory building work to do going forward. The exploration of the process of working with memory, the role of dialogue, and writing as a method of inquiry offer the potential to sharpen a focus on collective knowledge-making practices and possibilities in teaching anti-oppressive practices orientated towards the hope that 'Another world is not only possible, she is on her way. On a quiet day, I can hear her breathing.' Arundhati Roy [50] (p. 11).

Author Contributions: All authors contribute same to this paper. All authors have read and agreed to the published version of the manuscript.

Funding: This research received no external funding.

Institutional Review Board Statement: The study was conducted according to the guidelines of the Declaration of Helsinki, and approved by the Institutional Review Board University of Plymouth Education Research Sub Committee Plymouth Institute of Education, reference: 19/20-292.

Informed Consent Statement: Informed consent was obtained from all subjects involved in the study.

Data Availability Statement: Not applicable.

Acknowledgments: Janet Batsleer and all the participants in the collective biography process whose voices are present in the article but who aren't named as authors.

Conflicts of Interest: The authors declare no conflict of interest.

\section{References}

1. Ball, S.J. Foucault, Power and Education; Routledge: Abingdon, UK, 2013.

2. Braidotti, R. "We" are in this together, but we are not one and the same. J. Bioethical Inq. 2020, 17, 465-469. [CrossRef] [PubMed]

3. Freire, P. Pedagogy of the Oppressed; Continuum: New York, NY, USA, 1970. 
4. Charteris, J.; Nye, A.; Jones, M. Post humanist ethical practice: Agential cuts in the pedagogic assemblage. Int. J. Qual. Stud. Educ. 2019, 32, 909-928. [CrossRef]

5. Gale, K. Madness as Methodology. Bringing Concepts to Life in Contemporary Theorising and Inquiry; Routledge: Abingdon, UK, 2018.

6. Davies, B.; Gannon, S. (Eds.) Doing Collective Biography, Berkshire; Open University Press: London, UK, 2006.

7. Batsleer, J. Re-Assembling anti Oppressive Practice. 2021; in press.

8. Curran, S.; Gormally, S.; Smith, C. Reimagining Approaches to Teaching: Youth and Community Work Education. 2021; in press.

9. Cottam, H. Radical Help: How We Can Remake the Relationships between Us and Revolutionise the Welfare State; Virago: London, UK, 2018.

10. Zurbhoff, S. The fight for a human future at the new frontier of power. In The Age of Surveillance Capitalism; Profile Books Ltd.: London, UK, 2019.

11. Braidotti, R. The Posthuman; Polity Press: Cambridge, UK, 2013.

12. Seal, M. Critical realism's potential contribution to critical pedagogy and youth and, community work: Human nature, agency and praxis revisited. J. Crit. Realism 2016, 15, 263-276. [CrossRef]

13. Thompson, N. Anti-Discriminatory Practice: Equality Diversity and Social Justice: Practical Social Work, 5th ed.; Palgrave Macmillan: London, UK, 2012.

14. CLD. National Occupational Standards Youth Work. CLD Standards Council, 2019. Available online: https://cldstandardscouncil. org.uk/resources/standards-and-benchmarks/national-occupational-standards / (accessed on 14 May 2021).

15. Banks, S. Ethics that work. A critical review of ethics and values in teaching and practice-Papers from the Ethics \& Social Welfare Conference, London, 10 November 2008: Editorial Introduction. Ethics Soc. Welf. 2008, 3, 54-76.

16. Butler, J. Creating an Inhabitable World for Humans Means Dismantling Rigid Forms of Individuality, Time. Available online: https:/ / time.com/5953396/judith-butler-safe-world-individuality/ (accessed on 25 May 2021).

17. Ledwith, M. Community Development. A Critical and Radical Approach, 3rd ed.; Policy Press: Bristol, UK, 2020.

18. Seal, M. (Ed.) Teaching Youth Work in Higher Education; University of Tartu: Tartu, Estonia, 2019.

19. Haug, F. Female Sexualisation: A Collective Work of Memory; Verso: London, UK, 1987.

20. Davies, B. Entanglement in the World's Becoming and the Doing of New Materialist Inquiry; Routledge: Abingdon, UK, 2021.

21. Sivanandan, A. From resistance to rebellion: Asian and afro-Caribbean struggles in Britain. Race Cl. 1981, 23, 111-152. [CrossRef]

22. Sivanandan, A. Communities of Resistance: Writings on Black Struggles for Socialism; Verso Press: London, UK, 1990.

23. Sivanandan, A. A Different Hunger: Writing on Black Resistance; Pluto Press: London, UK, 1991.

24. Ramamurthy, A. Black Star: Britain's Asian Youth Movements; Pluto Press: London, UK; Wilson: Chicago, IL, USA, 2013.

25. Amrit, W. Finding a Voice: Asian Women in Britain, 2nd ed.; Virago Press: London, UK, 2018.

26. Davies, B. From Thatcherism to New Labour. A History of the Youth Service in England; Youth Work Press: Leicester, UK, 1999; Volume 2.

27. Amos, V.; Parmar, P. Resistances and responses: The experience of black girls in Britain. In Feminism for Girls: An Adventure Story; McRobbie, A., McCabe, T., Eds.; Routledge and Kegan Paul: London, UK, 1981; pp. 129-152.

28. Williams, L. Partial Surrender: Race and Resistance in the Youth Service; Falmer: London, UK, 1988.

29. Chauhan, V. Beyond Steel Bands ' $n$ ' Samosas; National Youth Bureau: Leicester, UK, 1990.

30. Collins, P.-H. Black Feminist Thought: Knowledge, Consciousness, and the Politics of Empowerment; Routledge: London, UK, 2000.

31. Hooks, B. Writing Beyond Race: Living Theory in Practice; Routledge: London, UK, 2013.

32. Khan, S. Challenging Hateful Extremism, Commission for Countering Extremism. 2019. Available online: https: //assets.publishing.service.gov.uk/government/uploads/system/uploads/attachment_data/file/836538/Challenging_ Hateful_Extremism_report.pdf (accessed on 17 May 2021).

33. Sue, D.W. Overcoming Our Racism: The Journey to Liberation; Jossey-Bass: San Francisco, CA, USA, 2003.

34. Garner, S. Racisms: An Introduction; Sage: London, UK, 2017.

35. Rutherford, A. How to Argue with a Racist: History, Science, Race and Reality; Orion Publishing: London, UK, 2020.

36. Schwarz, B. The White Man's World: Memories of Empire; Oxford University Press: Oxford, UK, 2011.

37. Olusoga, D. Black and British: A Forgotten History; MacMillan: London, UK, 2016.

38. Craig, G. (Ed.) Community Organising against Racism: 'Race', Ethnicity and Community Development; Policy Press: Bristol, UK, 2018.

39. Sinclair, T. A Perspective Approach to Training Community Workers; Goldsmiths College, University of London: London, UK, 1993.

40. Bowler, R. Critical youth and community work and its struggle with white standards. In Community Organising against Racism: 'Race', Ethnicity and Community Development; Craig, G., Ed.; Policy Press: Bristol, UK, 2018; pp. 41-60.

41. Fox, N.; Alldred, P. New materialist social inquiry: Designs, methods, and the research-assemblage. Int. J. Soc. Res. Methodol. 2015, 18, 399-414. [CrossRef]

42. Barad, K. Meeting the Universe Halfway. Quantum Physics and the Entanglement of Matter and Meaning; Duke University Press: Durham, NC, USA, 2007.

43. Harraway, D. Staying with the Trouble. Making Kin in the Chthulucene; Duke University Press: Durham, NC, USA, 2016.

44. Huyssen, A. Present Pasts: Urban Palimpsests and the Politics of Memory; Stanford University Press: Palo Alto, CA, USA, 2003.

45. St Pierre, E. Methodology in the fold and the irruption of transgressive data. Int. J. Qual. Stud. Educ. 1997, 10, 175-189. [CrossRef]

46. Ulmer, J. Posthumanism as research methodology: Inquiry in the Anthropocene. Int. J. Qual. Stud. Educ. 2017, 30, 832-848. [CrossRef] 
47. Davies, B.; Sommerville, M.; Claiborne, L. Feminist post structuralisms and the neo liberal university. In Qualitative Inquiry in Neoliberal Times; Denzin, N., Giardina, M., Eds.; Routledge: London, UK, 2017.

48. Beck, D.; Purcell, R. Anti-Oppressive Practice, in Community Development for Social Change; Routledge: London, UK, 2020.

49. Soyini, M. Critical Ethnography: Method, Ethics, and Performance, 3rd ed.; Sage: London, UK, 2019.

50. Roy, A.; Barsamian, D. The Checkbook and the Cruise Missile: Conversations with Arundhati Roy; Southend Press: Boston, MA, USA, 2004. 